\title{
Organic Amendments with Chemical Fertilizers Improve Soil Fertility and Microbial Biomass in Rice-Rice-Rice Triple Crops Cropping Systems
}

\author{
Md. Farid Ahammed Anik1, Md. Mizanur Rahman², G. K. M. Mustafizur Rahman², \\ Md. Khairul Alam ${ }^{1,3 *}$, Mahammad Shariful Islam1, Mst Fatima Khatun1 \\ ${ }^{1}$ Soil Science Division, Bangladesh Agricultural Research Institute, Gazipur, Bangladesh \\ ${ }^{2}$ Department of Soil Science, Bangabandhu Sheikh Mujibur Rahman Agricultural University, Gazipur, Bangladesh \\ ${ }^{3}$ School of Veterinary and Life Sciences, Murdoch University, Perth, Western Australia \\ Email: ${ }^{*}$ Khairul.krishi@gmail.com
}

How to cite this paper: Md. Anik, F.A., Md. Rahman, M., Rahman, G.K.M.M., Md. Alam, K., Islam, M.S. and Khatun, M.F. (2017) Organic Amendments with Chemical Fertilizers Improve Soil Fertility and Microbial Biomass in Rice-Rice-Rice Triple Crops Cropping Systems. Open Journal of Soil Science, 7, 87-100.

https://doi.org/10.4236/ojss.2017.75007

Received: April 12, 2017

Accepted: May 28, 2017

Published: May 31, 2017

Copyright $\odot 2017$ by authors and Scientific Research Publishing Inc. This work is licensed under the Creative Commons Attribution International License (CC BY 4.0).

http://creativecommons.org/licenses/by/4.0/ (c) (i) Open Access

\begin{abstract}
Medium-term changes in the labile nutrient pool of microbial biomass carbon $(\mathrm{MBC})$ and nitrogen $(\mathrm{MBN})$ resulting from organic manure application in rice (Oryza sativa L.)-based triple cropping systems have been poorly studied. Therefore, the effects of organic materials on the soil physico-chemical properties and microbial biomass in rice fields were investigated at Bangabandhu Sheikh Mujibur Rahman Agricultural University, Bangladesh, from April 2010 to December 2012. Five treatments (control, cow dung, poultry manure, rice straw, and chemical fertilizer) were laid out in a randomized complete block design with four replications. The organic residues $\left(2 \mathrm{t} \mathrm{C} \mathrm{ha}{ }^{-1}\right)$ were applied 7 days before transplanting and were combined with inorganic fertilizers, following integrated plant nutrition systems. This paper presents the results from the last of the five consecutive rice growing seasons. All of the organic residues increased the $\mathrm{pH}$, and organic $\mathrm{C}, \mathrm{N}, \mathrm{P}$, and $\mathrm{K}$ contents of the soil. However, poultry manure was more efficient in increasing soil fertility than cow dung and rice straw, resulting in a significant increase in P from 22 $\mathrm{mg} \cdot \mathrm{kg}^{-1}$ to $63 \mathrm{mg} \cdot \mathrm{kg}^{-1}$ at crop harvest. All of the organic residues also increased the soil water holding capacity and decreased bulk density. Furthermore, poultry manure resulted in significantly higher microbial biomass $\mathrm{C}$ (432 mg.kg-1 $P<0.05)$ and $\mathrm{N}\left(31.60 \mathrm{mg} \cdot \mathrm{kg}^{-1} ; P<0.05\right)$ levels in the soil at crop harvest, followed by cow dung and rice straw. These findings indicate that the regular application of organic residues and manures will help to enhance soil fertility and production sustainability.
\end{abstract}

\section{Keywords}

Integrated Plant Nutrition Systems (IPNS), Poultry Manure, Rice Straw, 
Water Holding Capacity

\section{Background}

The soil microbial biomass (SMB) indicates the ecological and biological quality and fertility of the soil, and is affected by organic/inorganic fertilizer application [1]. The SMB is involved in soil biogeochemical processes in soil-water-plant systems [1] [2], not only driving the nutrient cycle in agro-ecosystems, but also playing a vital role in soil nutrient transformations and acting as a labile nutrient pool that is available to plants [3] [4]. Several studies have emphasized the effects of organic manures such as soil organic carbon (SOC) on soil physicochemical properties. However, SOC may take a very long time to increase [5] [6] and observation of SOC changes alone may not explain the effect of organic matter on nutrient availability via microbiological activities. Alternatively, soil microbial biomass, which measures changes in both SOC and total soil nitrogen (TSN), can be used as a management indicator for soil fertility and crop productivity [7]. However, the effects of the various influencing factors, such as climatic and edaphic factors, fertilizer use, and crop establishment practices, on SMB are difficult to quantify due to their interactions; and estimation of the spatial and temporal distribution of SMB on the basis of limited field observations are even more difficult [4] [8].

Conventional agriculture on the Indo-Gangetic Plains is in a fragile state due to the overexploitation of land and water resources, and the indiscriminate use of agrochemicals [9] which reduce the diversity and quantity of microbes in the soil [10]. The use of different organic and inorganic fertilizers improves crop yields and also has direct or indirect effects on the physicochemical and biological properties of the soil. These changes are believed to have a significant effect on the quality and productive capacity of the soil on a long-term basis [11]. However, existing information on this issue is scarce and the long-term effects of organic inputs in combination with synthetic fertilizers on SMB have not been duly addressed.

Rice (Oryza sativa L.)-based cropping systems in the Indo-Gangetic Plains are very resource consumptive and input intensive [12] [13]. Though farmers use chemical fertilizers, the rates and methods of application are not justified according to either the integrated nutrient management system (INMS) or the integrated plant nutrition system (IPNS), and so most of the applied fertilizers are lost through various channels. Determination of microbial biomass carbon $(\mathrm{MBC})$ and nitrogen $(\mathrm{MBN})$ levels is crucial for the determination of $\mathrm{C}$ and $\mathrm{N}$ dynamics in rice systems, which regulate the SOC and $\mathrm{N}$ availability and loss, particularly in high-input-dependent cropping systems [14]. However, little research has investigated the effects of organic amendments on MBC and MBN in rice cropping systems, particularly in the eastern part of the Gangetic Plains, limiting our ability to generalize about soil $\mathrm{C}$ and $\mathrm{N}$ dynamics in subtropical cli- 
matic areas. Therefore, there is an urgent need to study how soil fertility and microbial biomass change with organic amendments under intensive rice-based cropping systems.

The micro-organismal growth and activities are affected by different factors depending on soil type and management practices [15]. Soil microbes are active drivers of soil nutrient cycling, being associated with the decomposition of organic matter, and the transformation and cycling of nutrients, which help to maintain crop productivity and the physical and chemical quality of the soil [16]. Thus, an improved understanding and quantification of the effect of organic residue applications on MBC and MBN, and soil properties will enhance our ability to manipulate nutrient cycling, to maintain and improve soil quality and production sustainability.

\section{Objectives}

Therefore, the study investigated the changes of $M B C$ and $M B N$ over the rice growing season; and effect of application of various organic residues in addition to chemical fertilizer on other soil characteristics after growing five consecutive rice crops.

\section{Materials and Methods}

This study was conducted at the experimental farm of Bangabandhu Sheikh Mujibur Rahman Agricultural University (BSMRAU), Gazipur, Bangladesh, as part of an ongoing research project entitled "Carbon sequestration in soils of Bangladesh," which ran from April 2010 to July 2012. This period covered five consecutive seasons of transplanted aman (T. aman) and boro rice, starting with $\mathrm{T}$. aman in 2010. Aman rice is grown as a rainfed crop during the monsoon season, when maximum rainfall occurs (300 - $650 \mathrm{~mm}$; supplemental irrigation is occasionally required when there is insufficient rainfall), while boro rice is grown after T. aman had been harvested under fully irrigated conditions during the dry season (0 - $55 \mathrm{~mm}$ rainfall). This report covers the last of the five consecutive growing seasons which was $\mathrm{T}$. aman season rice.

\subsection{Experimental Site and Climate}

The study site belongs to the Salna series and has been classified as Shallow Red-Brown Terrace soil (Inceptisol) under the US Department of Agriculture classification system [17]. The area is part of the Madhupur Tract agro-ecological zone (AEZ No. 28), in which the soils are acidic in nature and characterized by clay loam within $50 \mathrm{~cm}$ of the surface. The site is located at $24.09^{\circ} \mathrm{N}$ latitude and $90.25^{\circ} \mathrm{E}$ longitude, with an elevation of 8.2 meters above sea level. The experimental area experiences a subtropical climate, and is characterized by comparatively high levels of rainfall, high humidities, high temperatures, and relatively long days from April to September, and minimum levels of rainfall, low humidities, low temperatures, and short days from October to March (Figure 1). 


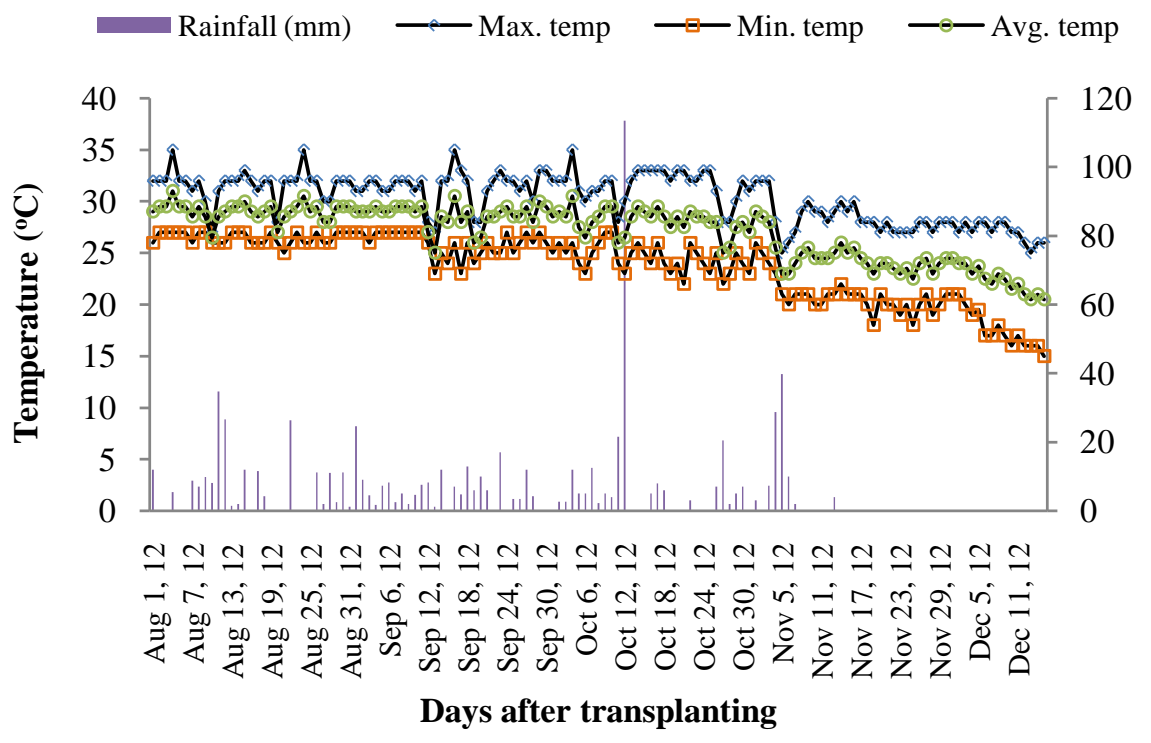

Figure 1. The maximum, minimum and average temperature $\left({ }^{\circ} \mathrm{C}\right)$ with line graphs (unit on the primary axis); the bars show the precipitation $(\mathrm{mm})$ in the area over the growing season (unit on the secondary axis).

\subsection{Experimental Treatments}

The experimental crop was rice and variety BRRI dhan39 was procured from Bangladesh Rice Research Institute (BRRI), Gazipur, Bangladesh and used as the experimental crop. This variety is non-photosensitive, short-duration. The grains are long slender and kernels are white. This variety takes about 130 to 145 days to mature. It attains a plant height of $95-100 \mathrm{~cm}$ and at maturity the flag leaf remains green and erect. The experiment comprised five treatments $\left(\mathrm{T}_{1}=\right.$ Control [no fertilizer]; $\mathrm{T}_{2}=$ cow dung; $\mathrm{T}_{3}=$ poultry manure; $\mathrm{T}_{4}=$ rice straw; and $\mathrm{T}_{5}=$ soil test based chemical fertilizer [STB]), which were laid out in a randomized complete block design with four replications per treatment. IPNS-based chemical fertilizers were applied in combination with treatments $T_{2}, T_{3}$, and $\mathrm{T}_{4}$. The organic materials were applied 7 days before transplanting at $2 \mathrm{t} \mathrm{C} \mathrm{ha}^{-1}$ during the Aman seasons.

On August 5, 2012, 30-day-old rice seedlings were transplanted into the experimental plots at $20 \mathrm{~cm} \times 20 \mathrm{~cm}$ spacing. The recommended doses of chemical fertilizers were calculated based on soil test results. Urea was applied in three equal parts, whereby one-third of the urea and the entire amount of triple superphosphate (TSP), murate of potash (MOP), and gypsum were applied during final land preparation; one-third of the urea was applied at the maximum vegetative growth stage (30 days after transplanting [DAT]); and one-third of the urea was applied before the panicle initiation stage of boro season rice (45 DAT).

Irrigation was used to keep the paddy field well flooded until the rice plants reached maturity. This was applied at $1,5,10,20,30,40,48,54,63$, and $78 \mathrm{DAT}$, with a total of $45 \mathrm{~cm}$ of irrigation water being applied during rice growth. Weeding was performed at 25 DAT. Precautionary measures were taken at every stage of crop production using natural methods of pest and disease manage- 
ment, such as light traps, the placement of sticks for birds to stand on, and the removal of disease-infected plants at an early stage of infection, removing any need for chemical and herbicide use.

\subsection{Soil Sample Collection and Processing}

Soil samples were collected from depths of 0 - 5, 5 - 10 and $10-15 \mathrm{~cm}$ separately at $0,30,60,90$, and $120 \mathrm{DAT}$, and were immediately placed in separate labeled ice bags to minimize microbial activity. The samples were then taken to the BSMRAU Soil Science Laboratory for analysis as quickly as possible to preserve their field properties. In the laboratory, they were spread out for partial air drying following removal of the roots, insects, worms, stones, and some small pieces of organic matter. This procedure was necessary to reduce the excess soil moisture and to allow the samples to be passed through a 2-mm mesh sieve. After sieving, part of each sample was kept in a polythene bag and incubated aerobically for 3 weeks at $25^{\circ} \mathrm{C}$ to remove the effect of handling on soil respiration. The remainder of each sample was fully air dried, ground, passed through a $2-\mathrm{mm}$ sieve, and then stored in a clean polythene bag for physical and chemical analysis.

The soil samples were analyzed for bulk density, $\mathrm{pH}, \mathrm{SOC}$, total $\mathrm{N}$, available $\mathrm{N}$ (mineral $\mathrm{N}$ ), available $\mathrm{P}$, exchangeable $\mathrm{K}, \mathrm{MBC}$, and $\mathrm{MBN}$. The maximum water holding capacity was also determined. Initial soil samples were also collected at 0 - $15 \mathrm{~cm}$ depth and analyzed for $\mathrm{pH}, \mathrm{SOC}$, total $\mathrm{N}$, available $\mathrm{P}$, and exchangeable $\mathrm{K}$.

\subsection{Methods of Soil Analysis}

The soil bulk density was determined using the core sampling method, as outlined by Karim et al. [18]. Soil $\mathrm{pH}$ was measured with a glass electrode $\mathrm{pH}$ meter (Horiba $\mathrm{pH}$ meter $\mathrm{M}-8 \mathrm{~L}$ ) using a soil water suspension ratio of 1:2.5, as described by Jackson [19].

Maximum water holding capacity (MWHC) and adjustment of soil moisture at $60 \%$ MWHC were performed as suggested by Haider et al. [20]. Maximum water holding capacity (MWHC) of the soil was estimated by placing a quantity of soil $(25 \mathrm{~g})$ in a glass funnel lined with filter paper. Distilled water was then poured into the funnel and allowed to drain out for at least 1 hour. Following this, a small amount of soil was removed and placed in a pre-weighed aluminum can, and the combined weight was noted. The soil was then dried in an oven at $105^{\circ} \mathrm{C}$ for at least 24 hours until it attained a constant weight. The ratio of the weight of soil water to the weight of oven-dried soil was considered the MWHC of the soil. To adjust the soil samples to $60 \%$ MWHC, the difference between the initial moisture content of the soil and 60\% MWHC was calculated, and the measured amount of water was then added to the samples.

Soil organic carbon (SOC) was estimated using Walkly and Black's wet oxidation method, as described by Jackson [19]. Total nitrogen was determined using the micro-Kjeldahl method [21], available P was measured using Olsen's method 
[22], and exchangeable $\mathrm{K}$ was estimated using the ammonium acetate extraction method [23].

\subsection{Measurements of Microbial Biomass C and N}

The chloroform fumigation extraction method was used to estimate the amount of microbial biomass $\mathrm{C}$ in the soil samples, according to the method described by Vance et al. [24]. Biomass $\mathrm{N}$ was determined according to the method described by Brookes et al. [25] [26].

\subsection{Statistical Analysis}

SPSS statistical software was used to analyze the data using one-way analysis of variance (ANOVA) and univariate analysis. Means were separated using the least significant difference (LSD) test at the 95\% confidence level.

\section{Results}

\subsection{Soil Chemical Properties}

The initial soil samples indicated that the soil in the study area was slightly acidic, and contained medium SOC, very low N, optimum $\mathrm{P}$, and low $\mathrm{K}$ contents (Table 1), reflecting a low to medium overall fertility. After five consecutive rice growing seasons, the soil chemical properties significantly varied among treatments $(P<0.05)$, with soil $\mathrm{pH}$, SOC, and available $\mathrm{P}$ significantly increasing following application of the different organic residues (Table 1 ).

Table 1. Soil properties of the experimental field under different organic residues and chemical fertilizer management at harvest.

\begin{tabular}{|c|c|c|c|c|c|}
\hline \multirow[b]{2}{*}{ Treatment } & \multicolumn{5}{|c|}{ Soil properties } \\
\hline & $\mathrm{pH}$ & $\begin{array}{l}\text { Organic } \\
\text { carbon } \\
(\%)\end{array}$ & $\begin{array}{c}\text { Total } \\
\text { nitrogen } \\
(\%)\end{array}$ & $\begin{array}{c}\text { Available } \\
\text { phosphorus } \\
\left(\mu \mathrm{g} \cdot \mathrm{g}^{-1}\right)\end{array}$ & $\begin{array}{c}\text { Exchangeable } \\
\text { potassium } \\
\text { (meq } 100 \mathrm{~g}^{-1} \text { soil) }\end{array}$ \\
\hline $\begin{array}{l}\text { Initial soil } \\
\text { properties }\end{array}$ & 5.85 & 1.13 & 0.09 & 22.0 & 0.13 \\
\hline Rice straw ${ }^{\S}$ & 5.88 & 1.81 & 0.16 & 27.2 & 0.26 \\
\hline $\begin{array}{l}\text { Poultry } \\
\text { manure }^{\S}\end{array}$ & 7.17 & 1.83 & 0.19 & 63.3 & 0.23 \\
\hline Cow dung ${ }^{\S}$ & 5.89 & 1.45 & 0.19 & 36.0 & 0.22 \\
\hline $\begin{array}{l}\text { Soil test based } \\
\text { fertilizer }\end{array}$ & 5.82 & 1.25 & 0.15 & 28.3 & 0.17 \\
\hline Control & 5.59 & 1.17 & 0.13 & 18.2 & 0.15 \\
\hline $\mathrm{SE}( \pm)$ & 0.52 & 0.10 & 0.82 & 1.22 & 0.83 \\
\hline $\mathrm{LSD}_{0.05}$ & 0.16 & 0.32 & NS & 3.76 & NS \\
\hline CV (\%) & 1.70 & 1.70 & 13.6 & 7.9 & 8.5 \\
\hline
\end{tabular}

Legends: SE $( \pm)$ means standard error of means; $\mathrm{LSD}_{0.05}$ means least significant differences at $5 \%$ level of significance and CV (\%) are coefficient of variations. ${ }^{\S}$-nutrient content in the organic amendment was deducted from recommended fertilizer dose. 
Soil $\mathrm{pH}$ was significantly higher in the poultry manure treated plots $(\mathrm{pH} 7.17)$ than in the control plots ( $\mathrm{pH}$ 5.59) and the initial soil samples $(\mathrm{pH} \mathrm{5.85)}(P<$ 0.05 ). This reflected a $23 \%$ increase compared with the initial soil $\mathrm{pH}$.

Plots that were treated with a combination of organic residues and chemical fertilizers also had significantly higher SOC contents than the control plots $(P<$ $0.05)$. Soil organic $C$ concentrations in the rice straw $(1.81 \%)$ and poultry manure $(1.83 \%)$ treated plots were statistically similar $(P>0.05)$, but significantly higher than the cow dung treated plots $(1.45 \% ; P<0.05)$. By contrast, the plots that were only treated with chemical fertilizer had a significantly lower SOC (1.25\%) than all of the organic residue treated plots.

Available $\mathrm{P}$ was greatly enhanced in the poultry manure treated plots $(P<$ 0.05 ; Table 1), increasing from an initial level of $22 \mathrm{mg} \mathrm{P} \mathrm{kg}{ }^{-1}$ soil to $63 \mathrm{mg} \cdot \mathrm{kg}^{-1}$. The cow dung treated plots also had $14 \mathrm{mg} \cdot \mathrm{kg}^{-1}$ more available $\mathrm{P}$ than the initial soil, whereas the control plots experienced a $3.78 \mathrm{mg} \cdot \mathrm{kg}^{-1}$ depletion in available P.

\subsection{Soil Biomass Carbon}

The MBC content of the soil varied between treatments at $0,30,60,90$, and 120 DAT (Table 2). The significant difference on transplanting day (day 0; $P<0.05$ ) was due to the experiment starting back in 2010. This was observed not only on transplanting day, but also found in 30,60,90 and 120 days after transplanting (Table 2). Irrespective of residues or for all treatments, the soil MBC contents increased with advancement of the rice growing period, i.e., maximum $\mathrm{MBC}$ was found at crop harvest and followed the order $0<30<60<90<120$ DAT. Soil $\mathrm{MBC}$ contents were significantly higher in plots that were treated with organic residues than in the control plots $(P<0.05)$, with poultry manure having the greatest effect and rice straw having the least effect. Thus, the maximum $\mathrm{MBC}$ was found in the poultry manure treated plots at harvest $\left(432 \mathrm{mg} \cdot \mathrm{kg}^{-1}\right)$, while the

Table 2. Microbial biomass carbon $\left(\mathrm{mg} \cdot \mathrm{kg}^{-1}\right)$ in soil under different organic residues and chemical fertilizer management practices at different days after transplanting (DAT).

\begin{tabular}{|c|c|c|c|c|c|}
\hline \multirow{2}{*}{ Treatment } & \multicolumn{5}{|c|}{ Biomass carbon $\left(\mathrm{mg} \cdot \mathrm{kg}^{-1}\right)$ at different days after transplanting } \\
\hline & 0 & 30 & 60 & 90 & 120 \\
\hline Rice straw ${ }^{\S}$ & 32.5 & 47.5 & 67.5 & 182 & 305 \\
\hline Poultry manure ${ }^{\S}$ & 101 & 115 & 121 & 301 & 432 \\
\hline Cow dung ${ }^{\S}$ & 47.3 & 71.3 & 91.6 & 178 & 380 \\
\hline Soil test based fertilizer & 73.4 & 141 & 111 & 167 & 329 \\
\hline Control & 17.0 & 35.5 & 49.3 & 118 & 200 \\
\hline $\mathrm{SE}( \pm)$ & 0.78 & 12.4 & 4.58 & 9.42 & 14.7 \\
\hline $\operatorname{LSD}_{(0.05)}$ & 2.41 & 38.2 & 14.1 & 29.0 & 45.5 \\
\hline $\mathrm{CV}(\%)$ & 2.90 & 30.3 & 10.4 & 10.0 & 9.00 \\
\hline
\end{tabular}

Legends: SE $( \pm)$ means standard error of means; LSD $_{0.05}$ means least significant differences at $5 \%$ level of significance and CV (\%) are coefficient of variations. ${ }^{\$}$-nutrient content in the organic amendment was deducted from recommended fertilizer dose. 
lowest level was found in the control plots on transplanting day $\left(17 \mathrm{mg} \cdot \mathrm{kg}^{-1}\right)$.

\subsection{Soil Biomass Nitrogen}

The treatments also affected the MBN content of the soil at different days after transplanting the rice (Table 3 ) and significantly differed between each other on transplanting day $(P<0.05)$.

As observed for $\mathrm{MBC}$, the maximum $\mathrm{MBN}$ was recorded at crop harvest and followed the order $0<30<60<90<120$ DAT. Soil MBN contents were significantly higher in plots that were treated with organic residues than the control plots $(P<0.05)$, and poultry manure again had the greatest effect, followed by cow dung and then rice straw. Thus, at harvest, the maximum MBN was found in the poultry manure treated plots $\left(32 \mathrm{mg} \cdot \mathrm{kg}^{-1}\right)$, while the lowest was found in the control plots $\left(9.88 \mathrm{mg} \cdot \mathrm{kg}^{-1}\right)$.

\subsection{Soil Water Holding Capacity}

Organic amended soils had a significantly higher water holding capacity than the STB fertilizer and control treatments (Figure 2) after five consecutive rice cultivating seasons and repeated additions of the organic manures. The lowest water holding capacity was found in soil in the control plots (53\%). There was no significant difference in the water holding capacity of soil between the three organic residue treatments, but cow dung treated plots had the highest level while poultry manure treated plots had the lowest.

\subsection{Soil Bulk Density}

The soil bulk density varied significantly following the application of different organic residues in the surface soil layer (Table 4). However, the highest bulk density was found in the control plots, while the lowest was found in the cow dung treated plots at all soil depths. Thus, the bulk density varied from 1.29 to

Table 3. Microbial biomass nitrogen $\left(\mathrm{mg} \cdot \mathrm{kg}^{-1}\right)$ in soil under organic residues and chemical fertilizer management practices at different days after transplanting (DAT).

\begin{tabular}{|c|c|c|c|c|c|}
\hline \multirow{2}{*}{ Treatment } & \multicolumn{5}{|c|}{ Biomass nitrogen $\left(\mathrm{mg} \cdot \mathrm{kg}^{-1}\right)$ at different days after transplanting } \\
\hline & 0DAT & 30DAT & 60DAT & 90DAT & 120DAT \\
\hline Rice straw ${ }^{\S}$ & 4.65 & 6.81 & 8.41 & 15.5 & 18.2 \\
\hline Poultry manure ${ }^{\S}$ & 5.01 & 13.4 & 13.8 & 18.7 & 31.6 \\
\hline Cow dung ${ }^{\S}$ & 4.70 & 6.99 & 11.6 & 14.4 & 27.2 \\
\hline Soil test based fertilizer & 5.79 & 11.8 & 10.9 & 18.2 & 20.1 \\
\hline Control & 3.25 & 6.43 & 6.01 & 11.5 & 9.88 \\
\hline $\mathrm{SE}( \pm)$ & 0.17 & 0.65 & 0.53 & 1.48 & 1.30 \\
\hline $\operatorname{LSD}_{(0.05)}$ & 0.53 & 2.02 & 1.63 & 4.56 & 4.01 \\
\hline CV (\%) & 7.40 & 14.5 & 10.6 & 18.9 & 12.2 \\
\hline
\end{tabular}

Legends: SE $( \pm)$ means standard error of means; $\mathrm{LSD}_{0.05}$ means least significant differences at $5 \%$ level of significance and CV (\%) are coefficient of variations. ${ }^{\S}$-nutrient content in the organic amendment was deducted from recommended fertilizer rate. 
Table 4. Bulk density of soil under different organic residues and chemical fertilizer management practices at different depths.

\begin{tabular}{cccc}
\hline \multirow{2}{*}{ Treatment } & \multicolumn{3}{c}{ Bulk density $\left(\mathrm{g} \cdot \mathrm{cm}^{-1}\right)$ at different soil depth } \\
\cline { 2 - 4 } & $0-5 \mathrm{~cm}$ & $5-10 \mathrm{~cm}$ & $10-15 \mathrm{~cm}$ \\
\hline Rice straw $^{\S}$ & 1.36 & 1.31 & 1.45 \\
Poultry manure $^{\S}$ & 1.34 & 1.41 & 1.38 \\
Cow dung & 1.29 & 1.17 & 1.20 \\
Soil test based fertilizer & 1.38 & 1.47 & 1.44 \\
Control & 1.48 & 1.54 & 1.46 \\
$S E( \pm)$ & 0.14 & 0.24 & 0.27 \\
LSD & 0.05 & $\mathrm{~ns}$ & $\mathrm{~ns}$ \\
$\mathrm{CV}(\%)$ & 2.20 & 3.60 & 4.00 \\
\hline
\end{tabular}

Legends: SE $( \pm)$ means standard error of means; LSD $_{0.05}$ means least significant differences at $5 \%$ level of significance and CV (\%) are coefficient of variations. " nutrient content in the organic amendment was deducted from recommended fertilizer rate.

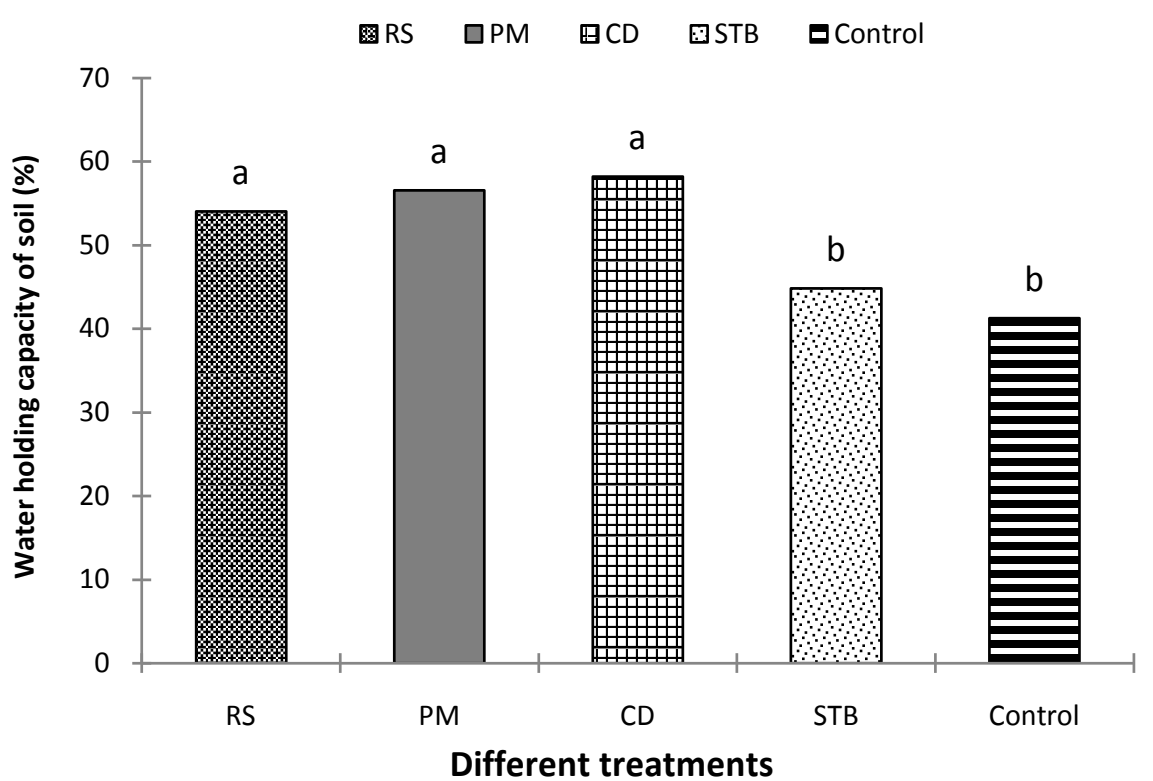

Figure 2. Water holding capacity of soil under different organic residues and chemical fertilizer management practices. RS-Rice straw + IPNS based chemical fertilizer, PM-poultry manure + IPNS based chemical fertilizer, CD-cow dung+ IPNS based chemical fertilizer, STB-soil test based chemical fertilizer and control. Vertical bars represent standard error of means.

$1.43 \mathrm{~g} \cdot \mathrm{cm}^{-3}$ in the top $0-5 \mathrm{~cm}$ of soil, from 1.17 to $1.47 \mathrm{~g} \cdot \mathrm{cm}^{-3}$ at a depth of 5 $10 \mathrm{~cm}$, and 1.20 to $1.44 \mathrm{~g} \cdot \mathrm{cm}^{-3}$ at a depth of $10-15 \mathrm{~cm}$ for the control and cow dung treated plots, respectively. Microbial biomass $\mathrm{C}$ and MBN are inversely related to the soil bulk density.

\section{Discussion}

At all sampling dates, $\mathrm{MBC}$ and $\mathrm{MBN}$ were significantly higher in the poultry manure treated plots than in the other treatment plots. This may have been due 
to the higher amounts of $\mathrm{N}$ that were present in the poultry manure resulting in a lower or optimum C:N ratio, favoring faster microbial colonization. These findings agree with those of several other studies [27] [28]. In addition, a higher amount of MBN was found in the STB fertilizer treatment than in the rice straw and cow dung treatments. This was due to the presence of higher amounts of available nutrients, particularly $\mathrm{N}$, in the fertilizer treatment, which favored rapid microbial activity, i.e., mineralization in the soils. These findings agree with those of Akmal et al. [29] who attributed higher microbial biomass to higher available $\mathrm{C}$ substrates and nutrient contents in soils. Thus, the availability of organic residues in the soils coupled with high moisture contents favored microbial activities, which ultimately contributed to the higher MBC and MBN under these treatments [30] [31].

The use of organic amendments in combination with chemical fertilizers improved the $\mathrm{pH}$, and SOC, N, P, and $\mathrm{K}$ contents of the soils after seven consecutive rice growing seasons. The use of poultry manure led to the greatest improvement in these initially low to medium fertility soils. Organic $\mathrm{C}$ was applied at a rate of $2 \mathrm{t} \mathrm{C} \mathrm{ha}^{-1}$ in all plots, irrespective of its source. However, poultry manure contains a higher amount of the stable form of $\mathrm{C}$, which explains the greater level of $\mathrm{C}$ enrichment in these plots. The higher $\mathrm{pH}$ in the poultry manure treated plots can be attributed to the presence of $\mathrm{Ca}$ in poultry manure due to the calcium-rich diet of poultry. The accumulation of $\mathrm{Ca}$ in the soil will have neutralized the soil acidity and ultimately increased the soil $\mathrm{pH}$ to around neutral levels. Finally, it is known that poultry manure usually contains a higher concentration of $\mathrm{P}$, with a previous study showing that at $30 \%-35 \%$ moisture level, poultry manure, cow dung, and rice straw contained $0.70 \%, 0.30 \%$, and $0.10 \% \mathrm{P}$, respectively [32]. Since the rate of $\mathrm{C}$ application in the present study was determined on an oven dry basis, the $\mathrm{P}$ accumulation will have been higher than these reported values. Therefore, the application of different organic residues improved soil fertility, with poultry manure being the most efficient organic amendment.

The soil water holding capacity also increased following the application of different organic residues (Figure 2), with rice straw, cow dung, and poultry manure having similar effects. The greatest improvement was recorded with poultry manure, which resulted in 38\% and 30\% higher levels than the control and STB fertilizer treated soils, respectively. Once again, this can be explained by the availability of organic residues in these soils coupled with their high moisture contents favoring microbial activities. These findings agree with those of Pavlova et al. [31] and Efremov et al. [30], who reported that the total pool of microbial biomass was dependent on the soil moisture content, which predetermined the water permeability of soils.

At the soil surface (top $0-5 \mathrm{~cm}$ ), organic amendment combined with chemical fertilizers significantly decreased the soil bulk density, and similar trends were observed at $5-10 \mathrm{~cm}$ and $10-15 \mathrm{~cm}$. This resulted from the organic residues favoring microbial biomass growth [33] and matches the findings of Glover 
et al. [34], who confirmed that the addition of organic residues with chemical $\mathrm{N}$ resulted in lower bulk densities and higher microbial biomass.

\section{Conclusion}

Poultry manure amendment in combination with chemical fertilizers under rice growing conditions resulted in the most biologically active soils with higher levels of $\mathrm{MBC}$ and $\mathrm{MBN}$. Thus, poultry manure is a more efficient organic amendment than cow dung and rice straw for increasing soil fertility. The application of organic residues also increased the $\mathrm{pH}$, and SOC, $\mathrm{N}, \mathrm{P}$, and $\mathrm{K}$ contents of the soil, further improving soil fertility. Compared with the initial soil, the poultry manure treatment increased the soil $\mathrm{pH}$ from an acidic (5.85) to neutral (7.17) state, SOC by $62 \%$, available P by $187 \%$, total $\mathrm{N}$ by $112 \%$, and exchangeable $\mathrm{K}$ by $77 \%$, though the latter two were similar to other organic amendments. The soil water holding capacity and bulk density increases that were observed following the application of organic residues reflected the microbial biomass improvements as a result of the same treatments, with poultry manure having the greatest effect and rice straw the least effect. The maximum $\mathrm{MBC}$ and $\mathrm{MBN}$ were found in the poultry manure treated plots at harvest (432 and $31.6 \mathrm{mg} \cdot \mathrm{kg}^{-1}$, respectively). Furthermore, irrespective of treatment, the biomass carbon contents increased with advancement of the rice growing period, i.e., $0<30<60<90<$ 120 DAT, with a maximum level at crop harvest. These findings show that the regular application of organic materials to soils using whatever sources available will increase the microbial dynamics and nutrient pools in the soil, enhancing soil fertility and productivity.

\section{Acknowledgements}

The study was conducted under the project "Carbon sequestration in soils of Bangladesh (ID \# 305)" funded by World Bank, IFAD \& Government of Bangladesh through Bangladesh Agricultural Research Council (BARC), NATP, Phase 1 and implemented by the Department of Soil Science, Bangabandhu Sheikh Mujibur Rahman Agricultural University, Gazipur, Bangladesh.

\section{Declaration of Conflict of Interest}

The Authors of the manuscript are hereby declared that there will not take place any conflicts of interest for any reasons, such as personal and/or financial relationships, academic competition, and intellectual passion. No gender issue is also involved in publishing the manuscript.

\section{Authors' Contributions}

All persons who meet authorship criteria are listed as authors, and all authors certify that they have participated sufficiently in the work to take public responsibility for the content, including participation in the concept, design, analysis, writing, or revision of the manuscript. Furthermore, each author certifies that this material or similar material has not been and will not be submitted to or 
published in any other publication before its appearance in The Journal of Agricultural Science and Technology.

\section{Funding/Support}

The work was supported by World Bank, IFAD \& Government of Bangladesh through Bangladesh Agricultural Research Council (BARC) [(ID \# 305)].

\section{References}

[1] Cerny, J., Balik, J., Kulhanek, M. and Nedved, V. (2008) The Changes in Microbial Biomass $\mathrm{C}$ and $\mathrm{N}$ in Long-Term Field Experiments. Plant, Soil and Environment, 54, 212-218.

[2] Laurie, A.T., Mary, A.A. and Ruth, D.Y. (1999) Forest Floor Microbial Biomass across a Northern Hardwood Successional Sequence. Soil Biology and Biochemistry, 31, 431-439.

[3] Jenkinson, D.S., et al. (1990) The Turnover of Organic Carbon and Nitrogen in Soil. Philosophical Transactions of the Royal Society B Biological Sciences, 329, 361-368.

[4] Wu, J., O’Donnel, A.G. and Syers, J.K. (1993) Microbial Growth and Sulfur Immobilization Following the Incorporation of Plant Residues into Soil. Soil Biology and Biochemistry, 25, 1567-1573.

[5] Hao, X.H., Liu, S.L., Wu, J.S., Hu, R.G., Tong, C.L. and Su, Y.Y. (2008) Effect of Long-Term Application of Inorganic Fertilizer and Organic Amendments on Soil Organic Matter and Microbial Biomass in Three Subtropical Paddy Soils. Nutrient Cycling in Agroecosystems, 81, 17-24. https://doi.org/10.1007/s10705-007-9145-Z

[6] Huang, Q.R., Hu, F., Huang, S., Li, H.X., Yuan, Y.H., Pan, G.X., et al. (2009) Effect of Long-Term Fertilization on Organic Carbon and Nitrogen in a Subtropical Paddy Soil. Pedosphere, 19, 727-734.

[7] Murphy, D.V., Sparling, G.P. and Fillery, I.R.P. (1998) Stratification of Microbial Biomass $\mathrm{C}$ and $\mathrm{N}$ and Gross N Mineralizsation with Soil Depth in Two Contrasting Western Australian Agricultural Soils. Australian Journal of Soil Research, 36, 45-55. https://doi.org/10.1071/S97045

[8] Liu, X.M., Zhao, K.L., Xu, J.M., Zhang, M.H., Si, B. and Wang, F. (2008) Spatial Variability of Soil Organic Matter and Nutrients in Paddy Fields at Various Scales in Southeast China. Environmental Geology, 53, 1139-1147.

https://doi.org/10.1007/s00254-007-0910-8

[9] Faroque, M.A.A., Kashem, M.A. and Bilkis, S.E. (2011) Sustainable Agriculture: A Challenge in Bangladesh. International Journal of Agricultural Research, Innovation and Technology, 1, 1-8.

[10] Fox, C.A. and MacDonald, K.B. (2003) Challenges Related to Soil Biodiversity Research in Agroecosystems-Issues within the Context of Scale of Observation. Canadian Journal of Soil Science, 83, 231-244. https://doi.org/10.4141/S01-059

[11] Rahman, M.M. (2013) Nutrient Use and Carbon Sequestration Efficiencies in Soils from Different Organic Wastes in Rice and Tomato Cultivation. Communications in Soil Science and Plant Analysis, 44, 1457-1471. https://doi.org/10.1080/00103624.2012.760575

[12] Alam, M.K., Biswas, W.K. and Bell, R.W. (2016) Greenhouse Gas Implications of Novel and Conventional Rice Production Technologies in the Eastern-Gangetic Plains. Journal of Cleaner Production, 112, 3977-3987.

[13] Alam, M.K., Salahin, N., Islam, M.M. and Hasanuzzaman, M. (2014) Effect of Till- 
age Practices on Soil Properties and Crop Productivity of Wheat-Mungbean-Rice Cropping System under Subtropical Climatic Conditions. The Scientific World Journal, 2014, Article ID: 437283. https://doi.org/10.1155/2014/437283

[14] Moore, J.M., Klose, S. and Tabatabai, M.A. (2000) Soil Microbial Biomass Carbon and Nitrogen as Affected by Cropping Systems. Biology and Fertility of Soils, 31, 200-210. https://doi.org/10.1007/s003740050646

[15] Yang, F., Wu, J.S., Qian, X.B. and Wu, L.-J. (2006) Dynamic Changes of Soil Microbial Biomass Carbon in Phyllostachys praecox Stand with Different Fertilizers. Journal of Zhejiang Forestry College, 23, 70-74.

[16] Lin, X.G., Yin, R., Zhang, H.Y., Huang, J.F., Chen, R.R. and Cao, Z.H. (2004) Changes of Soil Microbiological Properties Caused by Land Use Changing from Rice-Wheat Rotation to Vegetable Cultivation. Environmental Geochemistry and Health, 26, 119-128. https://doi.org/10.1023/B:EGAH.0000039574.99651.65

[17] USDA (1978) Soil Taxonomy. Agriculture Handbook No. 436, USDA, Soil Conservation Service, Washington DC.

[18] Karim, Z., Rahman, S.M., Idris, M. and Karim, A.J.M.S. (1988) A Manual for the Determination of Soil Physical Parameters. Soils and Irrigation Division, Bangladesh Agricultural Research Council, Dhaka, Bangladesh.

[19] Jackson, M.L. (1973) Soil Chemical Analysis. Prentice Hall of India (pvt). Ltd., New Delhi.

[20] Haider, J., Marumoto, T. and Azad, A.K. (1991) Estimation of Microbial Biomass Carbon and Nitrogen in Bangladesh Soils. Soil Science and Plant Nutrition, 37, 591599. https://doi.org/10.1080/00380768.1991.10416927

[21] Jackson, M.L. (1958) Soil Chemical Analysis. Prentice-Hall Inc., Englewood Cliffs, NJ, 498 p.

[22] Olsen, S.R. and Sommers, L.E. (1982) Phosphorus. In: Page, A.L., et al., Eds., Methods of Soil Analysis, 2nd Edition, Part 2, Agronomy No. 9, American Society of Agronomy, Madison, WI, 403-430.

[23] Baker, D.E. and Surh, N.H. (1982) Atomic Absorption and Flame Emission Spectroscopy. In: Page, A.L., Miller, R.H. and Keeney, D.R., Eds., Methods of Soil Analysis, Part 2, Chemical and Microbiological Properties, American Society of Agronomy Inc., Madison, WI, 13-26.

[24] Vance, E.D., Brookes, P.C. and Jenkinson, D.S. (1987) An Extraction Method for Measuring Soil Microbial Biomass. Soil Biology and Biochemistry, 19, 703-707.

[25] Brookes, P.C., Kragit, J.F., Powlson, D.S. and Jenkinson, D.S. (1985) Chloroform Fumigation and the Release of Soil Nitrogen. The Effects of Fumigation Time and Temperature. Soil Biology and Biochemistry, 17, 831-835.

[26] Brookes, P.C., Landsman, A., Pruden, G. and Jenkinson, D.S. (1985) Chloroform Fumigation and the Release of Soil Nitrogen. A Rapid Direct Extraction Method to Measure Microbial Biomass Nitrogen in Soil. Soil Biology and Biochemistry, 17, 837-840.

[27] Lovell, R.D., Jarvis, S.C. and Bardgett, R.D. (1995) Soil Microbial Biomass and Activity in Long-Term Grass Lands: Effects of Management Changes. Soil Biology and Biochemistry, 27, 969-975.

[28] Chang, X.C. and Juma, N.G. (1996) Impacts of Crop Rotations on Microbial Faunal Populations, and Plant Carbon and Nitrogen in Gray Luvisol (Typic Cryoralf). Biology and Fertility of Soils, 22, 31-39. https://doi.org/10.1007/BF00384429

[29] Akmal, M., Khan, K.S. and Xu, J.M. (2004) Dynamics of Microbial Biomass in a Rain Fed Soil under Wheat Cultivation. Pedosphere, 14, 53-62. 
[30] Efremov, A.L. (2000) Microbiota and Biogenic Nature of Alluvial Meadow Soils in the Pripyat Poles'e Region. Pochvovedenine, 5, 579-583.

[31] Pavlova, O.S., Polyanskaya, L.M., Kochkina, G.A. and Ivanushkina, N.E. (2000) Peculiarities of Microbial Succession in the Soils of Okskii Reserve. Pochvovedenie, 3 320- 328.

[32] FRG Fertilizer Recommendation Guide (2005) Bangladesh Agricultural Research Council (BARC). Farmgate, Dhaka 1215, 274 p.

[33] Rasiah, V. (1999) Nitrogen Immobilization and Mineralization in Legume-Amended Soils as Influenced by Texture and Compaction. Community Soil Science and Plant Analogy, 30, 829-841. https://doi.org/10.1080/00103629909370249

[34] Glover, J.D., Reganold, I.P. and Andrews, P.K. (2000) Systematic Method for Rating Soil Quality of Conventional Organic, and Integrated Apple Orchards in Washington State. Agriculture, Ecosystems \& Environment, 80, 29-43.

Submit or recommend next manuscript to SCIRP and we will provide best service for you:

Accepting pre-submission inquiries through Email, Facebook, LinkedIn, Twitter, etc. A wide selection of journals (inclusive of 9 subjects, more than 200 journals)

Providing 24-hour high-quality service

User-friendly online submission system

Fair and swift peer-review system

Efficient typesetting and proofreading procedure

Display of the result of downloads and visits, as well as the number of cited articles

Maximum dissemination of your research work

Submit your manuscript at: http://papersubmission.scirp.org/

Or contact ojss@scirp.org 